\title{
Ingestion of Amniotic Fluid Enhances Opiate Analgesia in Rats
}

\author{
MARK B. KRISTAL, ${ }^{1}$ ALEXIS C. THOMPSON AND PATRICIA ABBOTT \\ Department of Psychology, SUNY at Buffalo, Buffalo, NY 14260
}

Received 14 April 1986

\begin{abstract}
KRISTAL, M. B., A. C. THOMPSON AND P. ABBOTT. Ingestion of amniotic fluid enhances opiate analgesia in rats. PHYSIOL BEHAV 38(6) 809-815, 1986.-Placenta ingestion has recently been shown to enhance opiate-mediated analgesia produced by morphine injection, footshock, or vaginal/cervical stimulation. The enhancement of the effect of endogenous opiates (especially analgesia) may be one of the principal benefits to mammalian mothers of placentophagia at delivery. During labor and delivery, however, mothers also ingest amniotic fluid (AF) which, unlike placenta, becomes available during, or even before expulsion of the infant. The present experiments were undertaken to determine (a) whether $\mathrm{AF}$ ingestion, too, enhances analgesia; if so, (b) whether the effect requires ingestion of, or merely exposure to, $\mathrm{AF}$; (c) whether the effect can be produced by AF delivered directly to the stomach by tube; and (d) whether the enhancement, if it exists, can be blocked by administering an opiate antagonist. Nulliparous Long-Evans rats were tested for analgesia using tail-flick latency. We found that (a) rats that ingested AF after receiving a morphine injection showed significantly more analgesia than did rats that ingested a control substance; (b) AF ingestion, alone, did not produce analgesia; (c) ingestion of AF, rather than just smelling and seeing it, was necessary to produce analgesia enhancement; (d) AF produced enhancement when oropharyngeal factors were eliminated by delivering it through an orogastric tube; and (e) treatment of the rats with naltrexone blocked the enhancement of morphine-induced analgesia that results from AF ingestion.
\end{abstract}

Amniotic fluid Opiates Pain Tail-flick latency Placenta Analgesia Placentophagia Parturition Afterbirth Pregnancy Maternal behavior Morphine

WE have recently demonstrated that the effect of opiatemediated analgesia in rats (as measured by tail-flick latency) is enhanced if the rats ingest placenta, but not if they ingest ground beef or cookie mash. We have found this enhancement with morphine-induced analgesia [15], footshockinduced analgesia [15], and vaginal/cervical-stimulationinduced analgesia [16]. Furthermore, placenta does not seem to contain a substance that, by itself, is analgesic, since ingestion of placenta in the absence of an analgesia-producing treatment does not elevate pain threshold $[15,16]$. We have also demonstrated that the analgesia-enhancing effect of placenta ingestion seems to be specific to opiate-mediated analgesia, since treatment with naltrexone, an opiate antagonist, not only attenuates the analgesia produced by footshock, as expected, but also blocks the enhancing effect of placenta ingestion [15].

Endogenous opiate levels rise during pregnancy and delivery in both humans and rats $[4,6,9,12,13,19-23]$. Pain threshold has been observed to rise over the course of pregnancy in rats, and this "analgesia of pregnancy" has been demonstrated to be opiate mediated $[1,7,8]$. Enhancement of such analgesia, therefore, may be one of the principal benefits of parturitional placentophagia, and, in contrast to other hypotheses about advantages (e.g., nest hygiene, mother-infant attachment, reduction of predator-attracting stimuli $[14,17])$, this hypothesis suggests a benefit that would apply to virtually all species of mammals.
However, if placenta, alone, contains the substance that enhances opiate-mediated analgesia during the perinatal period, the fact that placenta is delivered after the neonate (anywhere from 5 to $75 \mathrm{~min}$ after) would render it effective only during the delivery of later infants in litters of mothers of polytocous species, or only in the postpartum period in mothers of monotocous species. On the other hand, if the opiate-enhancing substance is also present in amniotic fluid, then the effect on pain threshold would be realized during, if not before, delivery of the first infant, since amniotic fluid is available to the mother during and often before the emergence of the first infant.

The present series of experiments was designed to determine whether ingestion of amniotic fluid enhances opiate-mediated analgesia in rats. When we determined that it does, we then sought to determine whether the sight and smell of amniotic fluid could enhance analgesia, perhaps by producing an endorphin release in the same way that the sight of a cat produces an endorphin release in rats [5], whether oral sensory cues (e.g., taste) were involved in the response of the eater, and whether analgesia enhancement is specific to the opiate effects of morphine.

\section{EXPERIMENT 1}

In the first experiment we tested whether ingestion of amniotic fluid would elevate the tail-flick latencies of rats

${ }^{1}$ Requests for reprints should be addressed to Dr. Mark B. Kristal, Department of Psychology, Park Hall, State University of New York at Buffalo, Buffalo, NY 14260. 
that had received a threshold dose of morphine. The details of this experiment are almost identical to one reported previously [15].

\section{METHOD}

\section{Subjects}

Thirty-two virgin female Long-Evans rats, at least 90 days of age, and having normal estrous cycles, were used in this experiment. All rats were subjected to a $14 \mathrm{hr}$ on $/ 10 \mathrm{hr}$ off light/dark cycle, with the light phase beginning at 0600 (EST). Tests were conducted between 0800 and 1030 . Upon entry into the experiment, each rat was housed individually in a $24.5 \times 18 \times 18-\mathrm{cm}$ hanging, wire-mesh cage. Food (Agway Rat/Mouse/Hamster Formula 3000) and water were available ad lib, except for the 2 -hr period before testing, and during the actual tests. Pre-exposing the rats to the test material several times ensured that each future subject was willing to eat all the material presented, within a $15-\mathrm{min}$ period. All the rats in Experiment 1 had previously participated in another study in which they had been exposed to the intubation procedure described in Experiment 3, and had received one $3 \mathrm{mg} / \mathrm{kg}$ injection of morphine sulfate.

\section{Apparatus}

Pain thresholds were measured with the same "tail-flick" algesiometer described previously [15], which is similar to the standard apparatus used in many laboratories $[2,3]$. Heat produced by a $500-\mathrm{W}$ projecter lamp was beamed through a $1.8-\mathrm{cm}$ aperture at a rat's tail $2 \mathrm{~cm}$ away. When the heat became uncomfortable, the rat's tail moved and the stimulus was immediately terminated. The bulb output was monitored, and input was increased by means of a potentiometer, as the bulb aged. Initially, the bulb was set below maximum output, and was calibrated to produce a tail flick in 3-4 sec in a normal rat. If no response occurred, the trial was terminated at $8 \mathrm{sec}$ to prevent tissue damage in subjects experiencing analgesia. The number of seconds that elapsed before the rat moved its tail from the stimulus field after the onset of the heat (tail-flick latency, or TFL) was the dependent variable. Each TFL was the mean of the last 3 of 4 consecutive trials, which were separated by $30-\mathrm{sec}$ intervals. Rats were restrained in an opaque polyvinyl tube $(5 \times 21 \mathrm{~cm})$ to which they had been habituated previously.

\section{Procedure}

The 32 rats were evenly divided among four groups. The first and second groups received a threshold dose of morphine ( $3 \mathrm{mg} / \mathrm{kg}$ morphine sulfate, IP) followed by exposure to a mixture of either $1 \mathrm{ml}$ amniotic fluid in $1 \mathrm{~g}$ ground beef (Group M/AF) or $1 \mathrm{ml}$ beef bouillon in $1 \mathrm{~g}$ ground beef (Group M/BB). The third and fourth groups received saline rather than morphine $(1 \mathrm{ml} / \mathrm{kg}, \mathrm{IP})$ and were then presented with either the amniotic fluid + beef mixture (Group S/AF) or bouillon + beef mixture (Group S/BB).

Amniotic fluid was obtained surgically from Day 21 pregnant donors killed with $\mathrm{CO}_{2}$. The uterus was opened from the ends and the feto-placental units, each in its own sac, were extruded. A small puncture was made in the amniotic membrane and the amniotic fluid was drained into a glass dish. All the amniotic fluid collected from the fetuses of one adult was stored in one vial. The vials of amniotic fluid were quickly frozen at $-20^{\circ} \mathrm{C}$ and stored until needed. For presentation, each vial was warmed to $37^{\circ} \mathrm{C}$.

Beef bouillon (Wylers instant) was prepared in half the concentration specified in the directions, then frozen, stored and subsequently handled just as amniotic fluid.

For presentation, the amniotic fluid and beef bouillon (1 $\mathrm{ml}$ ) were mixed with $1 \mathrm{~g}$ fresh ground beef (sirloin). We felt that this would provide the rat with a substance that, in texture and composition, more closely approximated afterbirth material than did straight amniotic fluid. In addition, the beef mixture was easier to handle and present than a relatively thin liquid, and it was less likely to be refused by those nulliparous rats that apparently regard afterbirth material as aversive [14].

Each rat was food deprived for the 2 -hr period preceding the test, and food and water deprived during the test.

During the test, each subject first underwent a baseline TFL determination $\left(T_{b}\right)$, followed immediately by the morphine or saline injection. Fifteen minutes after injection, each rat was presented with the beef mixture in an untippable glass dish. After $20 \mathrm{~min}$, the rat was again tested for TFL $\left(T_{0}\right)$, then three more times at 30-min intervals $\left(T_{30}, T_{60}, T_{90}\right)$. This resulted in a $2 \times 2 \times 5$ design: Drug (morphine, saline) $\times$ "Food" (amniotic fluid + beef, bouillon + beef $) \times$ Time, with repeated measures on the Time variable.

The rat was housed in a holding cage during the intervals between TFL tests. For all the experiments reported here, the experimenter conducting the TFL tests was blind to the condition of the rats.

\section{RESULTS AND DISCUSSION}

The results of the first experiment are presented in Fig. 1. There were no significant differences between the mean baseline TFLs of the four groups: Group M/AF, 3.56 \pm 0.11 sec; Group M/BB, $3.52 \pm 0.04 \mathrm{sec}$; Group S/AF, 3.46 \pm 0.11 sec; Group $\mathrm{S} / \mathrm{BB}, 3.46 \pm 0.11 \mathrm{sec}$.

A 3-way ANOVA revealed a significant Food $\times$ Drug interaction, $\mathrm{F}(1,28)=6.39, p<0.01$, a significant main effect of Time, $\mathrm{F}(1,129)=7.84, p<0.001$ (with a GreenhouseGeisser probability correction), and a significant Time $\times$ Drug interaction, $\mathrm{F}(4,129)=3.08, p<0.05$ (with a GreenhouseGeisser correction).

Probes of the Food $\times$ Drug interaction on the different tests revealed that at $\mathrm{T}_{0}$, Group $\mathrm{M} / \mathrm{AF}$ (mean $=5.02 \pm 0.31$ $\mathrm{sec}$ ) showed significantly longer TFLs than Group M/BB $(3.80 \pm 0.16 \mathrm{sec}), \mathrm{F}(1,129)=20.59, p<0.01$, and than Group $\mathrm{S} / \mathrm{AF}(3.86 \pm 0.14), \mathrm{F}(1,129)=18.79, p<0.01$. There were no significant differences between Group $\mathrm{S} / \mathrm{AF}$ and Group $\mathrm{S} / \mathrm{BB}$, or between Group $\mathrm{M} / \mathrm{BB}$ and Group S/BB.

At $T_{30}$, the differences seen at $T_{0}$ were sustained: Group M/AF $(4.51 \pm 0.47 \mathrm{sec})$ showed significantly longer TFLs than either Group M/BB $(3.87 \pm 0.33 \mathrm{sec}), \mathrm{F}(1,129)=5.55$, $p<0.05$, or Group S/AF $(3.39 \pm 0.07 \mathrm{sec}), \mathrm{F}(1,129)=17.41$, $p<0.01$. There were no significant differences between Group S/AF $(3.39 \pm 0.07 \mathrm{sec})$ and Group S/BB $(3.57 \pm 0.12$ $\mathrm{sec})$, or between Group $\mathrm{M} / \mathrm{BB}(3.87 \pm 0.33 \mathrm{sec})$ and Group $\mathrm{S} / \mathrm{BB}$.

There were no significant differences between groups at either $\mathrm{T}_{60}$ or $\mathrm{T}_{90}$. There were no significant correlations between stage of the estrous cycle on the day of testing and the magnitude of the TFL.

The results of Experiment 1, that amniotic-fluid ingestion enhances analgesia produced by morphine injection, but 


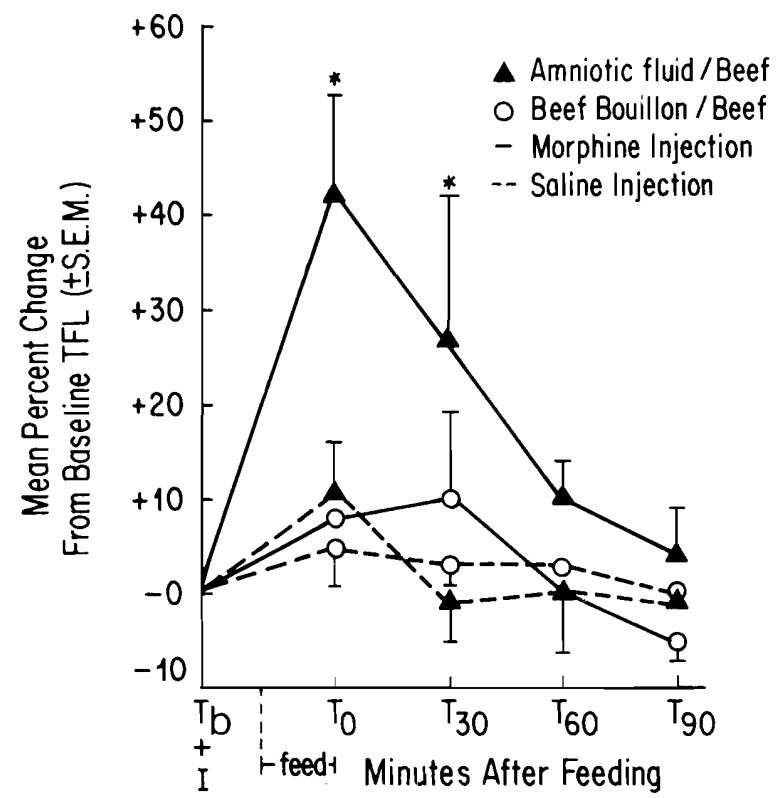

FIG. 1. Mean percent change from baseline $( \pm$ S.E.M. $)$ tail-flick latency (TFL) of rats that ate either amniotic fluid + beef or beef bouillon + beef, after receiving either a morphine $(3 \mathrm{mg} / \mathrm{kg}$, IP) or saline (1 $\mathrm{ml} / \mathrm{kg}$, IP) injection ( $\mathrm{n}=8 /$ group $)$. I = injection; $*=$ significantly different from all other groups, $p<0.01$.

does not, by itself, produce analgesia, are consistent with our previous report on the effects of placenta ingestion on morphine-induced analgesia [15]. The effect of amniotic-fluid ingestion is more modest than the effect of placenta ingestion: ingestion of $4 \mathrm{~g}$ placenta produced an increase in TFL of nearly $71 \%$ (over morphine controls) in $20 \mathrm{~min}$, whereas ingestion of $1 \mathrm{ml}$ amniotic fluid elevated TFL by about $30-35 \%$ in the same amount of time. There is no reason to assume, of course, that $4 \mathrm{~g}$ placenta and $1 \mathrm{ml}$ amniotic fluid are equivalent doses, but some pilot work we have conducted on different doses of amniotic fluid indicates that a $45-50 \%$ increase in TFL, over that produced by morphine alone, may be the maximum change.

\section{EXPERIMENT 2}

Apparently, rats show an endorphin release when confronted with certain "naturalistic activating" stimuli, such as the odors released from stressed rats [5], or the sight of a live cat [18]. Afterbirth material may be in the same category of stimuli for virgin rats; their response to it is intense but dichotomous. Some virgin rats (and mice) approach it and consume it immediately, completely, and avidly. The rest behave as if they are afraid of it, backing into a corner, attempting to leap out of the cage, or in the case of mice, rattling their tails [14].

It is possible then, that the opiate-enhancement effect we observed was due to the initial response the rats have to the smell and perhaps sight of the afterbirth material, rather than one specifically resulting from ingesting the material. In Experiment 1 and in our previous papers $[15,16]$, the rats that ate the material were the only ones that saw and smelled it. Therefore, the present experiment was designed to deter-

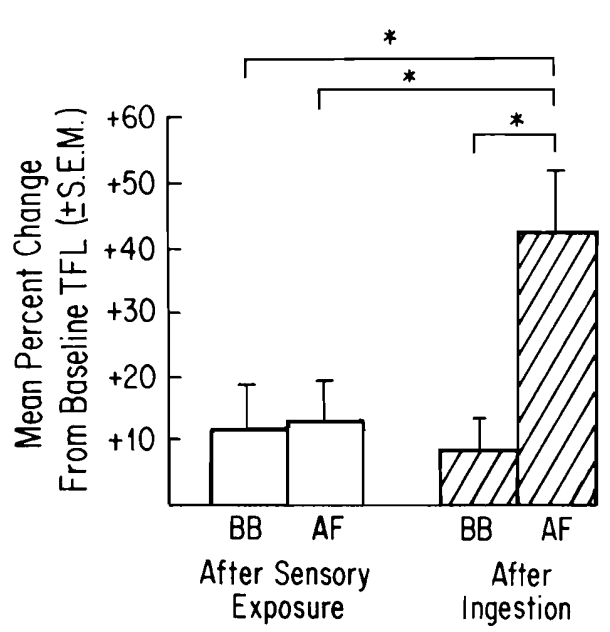

FIG. 2. Mean percent change from baseline ( \pm S.E.M.) tail-flick latency (TFL) of rats that received an injection of morphine (3 $\mathrm{mg} / \mathrm{kg}$, IP) and either ate amniotic fluid + beef or beef bouillon + beef, or were merely exposed to amniotic fluid + beef or beef bouillon + beef $(\mathrm{n}=8 /$ group; $*=p<0.01)$.

mine whether seeing and smelling amniotic fluid (and beef), but not ingesting it, is sufficient to produce enhancement of opiate-mediated analgesia.

\section{METHOD}

\section{Subjects}

Sixteen Long-Evans virgin female rats, at least 90 days of age and having regular estrous cycles, were used. All subjects had received a single injection of morphine sulfate (3 $\mathrm{mg} / \mathrm{kg}$ ) some weeks prior to the start of Experiment 2 . They were housed and fed identically to the rats in Experiment 1. Testing was conducted between 0800 and $1030 \mathrm{hr}$.

\section{Apparatus}

The TFL-testing apparatus was the same as that used in Experiment 1 .

\section{Procedure}

The procedures were the same as those used in Experiment 1 for the morphine-treated rats, except that the dish containing either beef bouillon + beef (Group BB/Expose) or amniotic fluid + beef (Group AF/Expose) was placed $5 \mathrm{~cm}$ beneath the center of the subject's cage. These subjects were exposed to amniotic fluid and bouillon before the test, as were the subjects in Experiment 1.

The rats in this experiment were compared to those of Experiment 1 that had ingested either bouillon + beef (Group $\mathrm{BB} /$ Ingest) or amniotic fluid + beef (Group AF/Ingest) after an injection of morphine sulfate $(n=8 /$ group $)$. This resulted in a $2 \times 2 \times 2$ design: "Food" (amniotic fluid + beef, 
bouillon + beef) $\times$ Treatment (ingestion, exposure) $\times$ Time (pre, post), with repeated measures on the Time factor.

\section{RESULTS AND DISCUSSION}

The results of the second experiment are presented in Fig. 2. A 3-way ANOVA revealed a significant Food $\times$ Treatment $\times$ Time interaction, $F(1,28)=4.93, p<0.05$. A probe of the Food $\times$ Treatment interaction in the baseline condition (pre) indicated that there were no significant differences between the groups $(\mathrm{BB} /$ Ingest $=3.53 \pm 0.04 \mathrm{sec} ; \mathrm{AF} /$ Ingest $=3.56 \pm 0.11$ sec: $\mathrm{BB} /$ Expose $=3.48 \pm 0.34 ; \quad \mathrm{AF} /$ Expose $=3.54 \pm 0.09 \mathrm{sec})$, $F(1,56)<1.00$

The only TFLs that changed significantly as a consequence of treatment (ingestion or exposure) were those of the group that ingested amniotic fluid (Group AF/Ingest). The TFLs of this group increased by about $40 \%$, whereas those of the other groups increased by only about $10 \%$. The increase in latency of Group AF/Ingest (pre $=3.56 \pm 0.11 \mathrm{sec}$; post $=5.02 \pm 0.31 \mathrm{sec}$ ) was significant, $\mathrm{F}(1,28)=28.5, p<0.01$. The increases in latency shown by the other three groups were not statistically significant. The post-treatment mean latency of Group $\mathrm{AF} /$ Ingest was also significantly greater than those of Groups $\mathrm{BB} /$ Ingest $(3.80 \pm 0.16 \mathrm{sec})$, $F(1,56)=21.3, p<0.01$, and $A F /$ Expose $(3.89 \pm 0.27 \mathrm{sec})$, $\mathrm{F}(1,56)=18.48, p<0.01$

Clearly, sensory exposure to amniotic fluid (and beef) did not enhance morphine-induced analgesia, whereas ingestion of amniotic fluid (and beef) did.

\section{EXPERIMENT 3}

It is possible that the enhancing effect of amniotic fluid ingestion on morphine analgesia, as observed in Experiment 1 , was due to oropharyngeal factors such as the taste, texture, or effect on mouth tissues, rather than due to the effect of the fluid in, or absorbed by, the stomach or intestine. It is also possible that the effect seen in Experiment 1 was the result of an interaction between amniotic fluid and beef. To test for these possible confounds, we examined the effect on morphine analgesia of amniotic fluid delivered directly to the stomach by means of an orogastric tube.

METHOD

\section{Subjects}

Eight virgin adult Long-Evans female rats, with regular estrous cycles, were used as subjects. They were housed and maintained as described in Experiment 1.

\section{Apparatus}

The experimental and control fluids were administered by means of an orogastric tube consisting of a $3.65-\mathrm{cm}$ curved, stainless steel intubation needle, having a $2.25-\mathrm{mm}$ ball end (Popper, Inc.). The needle was fitted to a 1-cc tuberculin syringe.

Pain thresholds were assessed using the TFL testing apparatus described in Experiment 1.

\section{Procedure}

Each rat was tested in each of four conditions: intubated

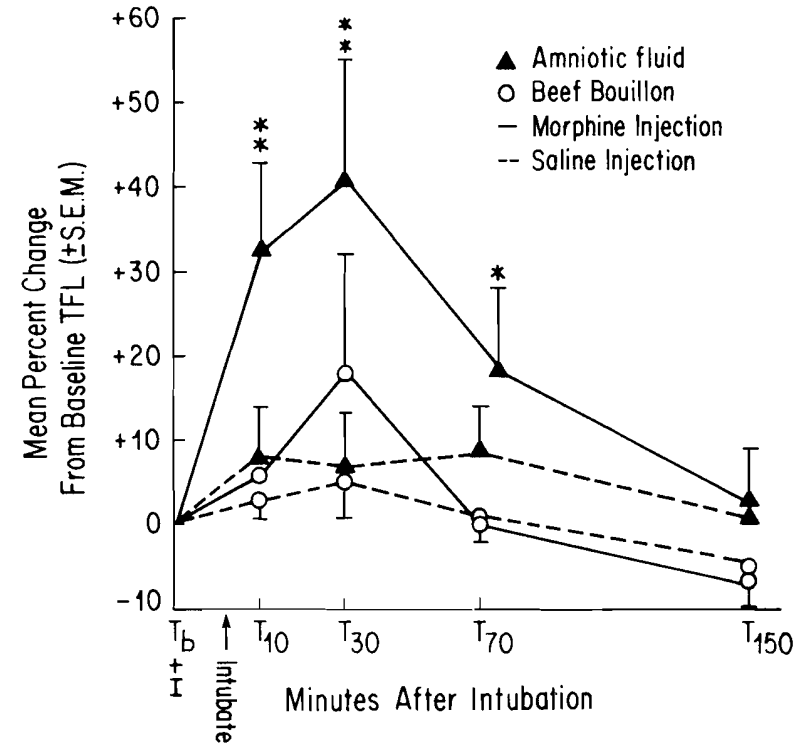

FIG. 3. Mean percent change from baseline ( \pm S.E.M.) tail-flick latency (TFL) of rats that received either amniotic fluid or beef bouillon by orogastric tube after receiving an injection of either morphine $(3 \mathrm{mg} / \mathrm{kg}$, IP) or saline ( $1 \mathrm{ml} / \mathrm{kg}$, IP) $(\mathrm{n}=8 /$ group $)$. $\mathrm{I}=$ injection; $* *=$ significantly different from all other groups, $p<0.01 ; *=$ significantly different from the morphine/beef bouillon group, $p<0.01$.

with amniotic fluid after morphine injection (Group M/AF); intubation with beef bouillon after morphine injection (Group $\mathrm{M} / \mathrm{BB}$ ); intubated with amniotic fluid after saline injection (Group S/AF); intubated with beef bouillon after saline injection (Group S/BB). The order of conditions was counterbalanced. The rats were given a 1 -week interval between conditions. In each condition, the rats were measured for baseline TFL $\left(T_{1}\right)$, injected with drug, 15 min later intubated with fluid, and then given TFL tests $10,30,70$, and $150 \mathrm{~min}$ after intubation $\left(\mathrm{T}_{10}, \mathrm{~T}_{30}, \mathrm{~T}_{70}, \mathrm{~T}_{150}\right)$. This resulted in a $2 \times 2 \times 5$ design: Drug (morphine, saline) $\times$ Fluid (amniotic fluid, beef bouillon) $\times$ Time, with repeated measures on all three variables.

Amniotic fluid was collected and stored as described in Experiment 1. Bouillon was mixed and stored as described in Experiment 1. These fluids were administered in a volume of $1 \mathrm{ml}$ over a period of $1 \mathrm{~min}$, to rats that had been food and water deprived for $3 \mathrm{hr}$. Each rat had been intubated five times before the first test day (no fluid was infused).

Testing was conducted between 0800 and $1400 \mathrm{hr}$.

\section{RESULTS AND DISCUSSION}

The baseline mean TFLs $\left(\mathrm{T}_{\mathrm{b}}\right)$ did not differ among the groups. They ranged from $3.29 \pm 0.16 \mathrm{sec}$ (Group $\mathrm{S} / \mathrm{AF}$ ) to $3.48 \pm 0.06 \mathrm{sec}$ (Group M/BB), F $(1,32)<1.00$.

The results of the third experiment are presented in Fig. 3. As in Experiment 1, the ingestion of amniotic fluid enhanced morphine analgesia, even when the amniotic fluid was delivered by stomach tube. The 3-way ANOVA revealed a significant Fluid $\times$ Drug interaction, $F(1,7)=7.97$, $p<0.05$, and a significant effect of Time, $F(4,28)=7.55$, $p<0.01$ (with a Greenhouse-Geisser correction).

The saline-injected rats (Groups S/AF and S/BB) showed no significant change from baseline TFL. 
TABLE 1

MEAN PERCENT CHANGE FROM BASELINE TAIL-FLICK LATENCY OF NALTREXONE- OR SALINETREATED RATS AFTER RECEIVING MORPHINE AND AFTER INGESTING EITHER AMNIOTIC FLUID OR BEEF BOUILLON

\begin{tabular}{|c|c|c|c|c|c|}
\hline \multirow[b]{3}{*}{ Fluid } & \multirow[b]{3}{*}{$\mathrm{n}$} & \multicolumn{4}{|c|}{ Test } \\
\hline & & \multicolumn{2}{|c|}{$T_{t 0}$} & \multicolumn{2}{|c|}{$\mathrm{T}_{30}$} \\
\hline & & Naltrexone & Saline & Naltrexone & Saline \\
\hline Amniotic Fluid & 8 & $+2.0 \pm 1.9$ & $+26.8 \pm 5.6^{*}$ & $-0.69 \pm 1.1$ & $+50.5 \pm 9.8 \dagger$ \\
\hline Beef Bouillon & 7 & $+2.7 \pm 2.7$ & $+14.0 \pm 7.1^{*}$ & $-1.89 \pm 1.8$ & $+7.9 \pm 6.9$ \\
\hline
\end{tabular}

*Significantly greater than baseline and naltrexone group, $p<0.01$.

$\dagger$ Significantly greater than all other means, $p<0.01$.

The morphine-injected group that received amniotic fluid had significantly longer TFLs than all other groups, and than its own baseline, at $T_{10}, F(1,32)=8.21, p<0.01$, and $T_{30}$, $\mathrm{F}(1,32)=7.21, p<0.01$. By $\mathrm{T}_{70}$, however, Group M/AF had TFLs that were significantly longer than only Group $\mathrm{M} / \mathrm{BB}$, $\mathrm{F}(1,62)=6.79, p<0.01$. By $\mathrm{T}_{150}$, there were no statistically significant differences among the groups.

Although some of the rats that were injected with a threshold dose of morphine, and that also received bouillon (Group M/BB), showed an elevation of TFL at $T_{30}$, the group did not differ significantly from the saline-injected groups.

These data were consistent with those of Experiment 1 and previous studies $[15,16]$ in also showing that amniotic fluid ingestion, in the absence of opiate-induced analgesia, does not produce analgesia.

\section{EXPERIMENT 4}

To verify that amniotic fluid specifically enhances the opiate-mediated effects of morphine, rats were tested in a design similar to that used in Experiment 3, except that half of them received treatment with the opiate-blocker naltrexone as part of the protocol.

METHOD

\section{Subjects}

Fifteen Long-Evans female rats, 90-150 days old, that had demonstrated regular estrous cyclicity were used. They were housed and maintained as described in Experiment 1.

\section{Apparatus}

The intubation instrument was an improved version of that described in Experiment 3; rather than a steel intubation needle, we used a blunted section of PE 205 tubing fitted to a 16-ga hypodermic needle.

Pain thresholds were assessed using the same TFL testing apparatus described in the preceding experiments.

\section{Procedure}

Each rat was assigned to one of the two Fluid groups (amniotic fluid, Group AF, $n=8$; beef bouillon, Group BB, $n=7$ ) and tested in each of two Drug conditions (naltrexone, saline). All rats received morphine $(3 \mathrm{mg} / \mathrm{kg}$, IP) on both tests, which occurred 1 week apart, and were balanced so that half the rats were tested with naltrexone first and the remainder tested with saline first. Each test consisted of several TFL determinations, resulting in a $2 \times 2 \times 4$ design: Fluid (amniotic fluid, beef bouillon) $\times$ Drug (naltrexone, saline) $\times$ Time, with repeated measures on the Drug and Time variables.

Since both morphine and Drug were injected, the sequence of procedures was slightly different from that described in Experiment 3. The rats were habituated to the restrainer and to the intubation procedure prior to testing, as described previously. Food and water were removed $3 \mathrm{hr}$ prior to the test. For the test, first a Pre-Naltrexone/PreMorphine baseline was determined. This was followed immediately by a Drug injection (naltrexone, $5 \mathrm{mg} / \mathrm{kg} \mathrm{SC}$, or saline, $1 \mathrm{ml} \mathrm{SC}$ ). After $20 \mathrm{~min}$, a Post-Naltrexone/PreMorphine baseline was determined $\left(\mathrm{T}_{\mathrm{b}}\right)$, and a morphine injection administered. Fifteen minutes later, the amniotic fluid or beef bouillon was intubated, and after $10 \min \left(\mathrm{T}_{10}\right)$ and $30 \mathrm{~min}\left(\mathrm{~T}_{30}\right)$, TFLs were again measured.

\section{RESULTS AND DISCUSSION}

A 2-way ANOVA determined that the Pre-Naltrexone/ Pre-Morphine and Post-Naltrexone/Pre-Morphine baselines were the same for both the naltrexone and saline groups (naltrexone: Pre $=3.36 \pm 0.08 \mathrm{sec} ;$ Post $=3.33 \pm 0.07 \mathrm{sec}$; saline: Pre $=3.36 \pm 0.06 \mathrm{sec}$; Post $=3.25 \pm 0.04 \mathrm{sec} ; \mathrm{F}(1,14)=$ $1.04, p>0.05$ ). Since the Pre-Naltrexone/Pre-Morphine and Post-Naltrexone/Pre-Morphine baselines were the same, only the Post-Naltrexone/Pre-Morphine baseline was used for subsequent comparisons.

The results of Experiment 4 are summarized in Table 1.

As in Experiment 3, in the absence of naltrexone, amniotic fluid significantly heightened morphine-induced analgesia at both 10 and $30 \mathrm{~min}$ after ingestion, $\mathrm{F}(2,52)=49.00, p<0.01$. In the presence of naltrexone, however, not only was there no effect of morphine on TFL, but amniotic fluid, too, was ineffective, $F(2,52)<1.00$. This is consonant with our previous report that the enhancing effect of placenta is specific to opiate-mediated analgesia [15].

\section{GENERAL DISCUSSION}

In Experiment 1 we showed that ingestion of amniotic 
fluid enhances opiate-mediated analgesia, but although the fluid contains opioids [11], it is not, by itself, an analgesic. These results are consistent with our previous reports on the effects of placenta-ingestion on opiate-mediated analgesia $[15,16]$. In Experiment 2 we demonstrated that the effect of amniotic fluid on opiate-mediated analgesia is the result of ingestion of the fluid, not a reaction to the smell and sight of the substance. In Experiment 3 we demonstrated that delivery of the fluid directly to the stomach, by means of an orogastric tube, led to the enhancement effect, suggesting that oropharyngeal factors such as taste (although that was not entirely ruled out by the intubation procedure), texture, and the necessity for chemical changes produced by components of saliva, were not important. In Experiment 4 we demonstrated that the analgesia-enhancing effect of amniotic-fluid ingestion is specific to the opiate-mediated analgesia produced by morphine.

The dose of morphine used ( $3 \mathrm{mg} / \mathrm{kg}$ ) was chosen because it is close to the threshold dose for the production of analgesia. In the present experiments, however, the elevation of TFL produced by morphine alone was considerably less than that in our previous reports. The rats in the earlier reports $[15,16]$ had had no previous exposure to morphine, whereas in the present experiments, the rats had had a prior morphine injection (Experiments 1 and 2) or had two injections during the course of the experiment (Experiments 3 and 4). We have found that the TFL responses to $3 \mathrm{mg} / \mathrm{kg}$ morphine are smaller and less variable if the rats had received a previous injection of the same dose of morphine weeks earlier. In the feeding paradigm, which was used in this and in our previous reports, the first morphine injection elevated TFL by about $35 \%$, but if the procedure was repeated weeks later, the same dose of morphine only produced an increase in TFL of about $10 \%$. In the intubation paradigm (such as that used in Experiments 3 and 4), the initial morphine treatment elevated TFL by about $20 \%$, whereas a repetition weeks later produced an elevation of about $12 \%$. This alteration in the response to morphine by as few as one prior treatment has been reported previously [10].

The finding that ingestion of amniotic fluid enhances opiate-mediated analgesia, as does ingestion of placenta, is particularly important for building a case that analgesia enhancement is a major advantage of ingesting amniotic fluid and placenta during and after delivery. If ingestion only of placenta produced enhancement of opiate analgesia, we would be hard-pressed to explain what advantage this would have for mothers delivering only one neonate. The need to reduce pain and discomfort is probably less after delivery (when the placenta becomes available) than it is during delivery. Amniotic fluid ingestion, though, also produces enhancement of opiate analgesia; since amniotic fluid is available early in the delivery process, and has an effect within minutes of ingestion, the advantage, as a reduction of pain during delivery, would be significant even to monotocous mothers. Of course, it is possible that, as we have hypothesized, the significant advantage of placentophagia is opiate-enhancement, but that the important opiate effect enhanced is not analgesia, but another process. Enhanced analgesia, therefore, might just be a desirable side-effect.

\section{ACKNOWLEDGEMENTS}

We thank Ken Levy for his helpful comments on an earlier version of this paper, and Dr. V. J. Nickolson of E. I. duPont de Nemours and Co. for generously supplying the naltrexone.

\section{REFERENCES}

1. Baron, S. A. and A. R. Gintzler. Pregnancy induced analgesia: effects of adrenalectomy and glucocorticoid replacement. Brain Res 321: 341-346, 1984

2. Bolles, R. C. and M. S. Fanselow. Endorphins and behavior. Annu Rev Psychol 33: 87-101, 1982.

3. D'Amour, F. E. and D. L. Smith. A method for determining loss of pain sensation. $J$ Pharmacol Exp Ther 72: 74-79, 1941.

4. Facchinetti, F., G. Centini, D. Parrini, F. Petraglia, N. D'Antona, E. V. Cosmi and A. R. Genazzani. Opioid plasma levels during labor. Gynecol Obstet Invest 13: 155-163, 1982.

5. Fanselow, M. S. Odors released by stressed rats produce opioid analgesia in unstressed rats. Behav Neurosci 99: 589-592, 1985.

6. Foley, K. M., I. A. Kourides, C. E. Inturrisi, R. F. Kaiko, C. G. Zaroulis, J. B. Posner, R. W. Houd and C. H. Li. $\beta$-Endorphin: Analgesia and hormonal effects in humans. Proc Natl Acad Sci USA 76: 5377-5381, 1979.

7. Gintzler, A. R. Endorphin-mediated increases in pain threshold during pregnancy. Science 210: 193-195, 1980.

8. Gintzler, A. R., L. C. Peters and B. R. Komisaruk. Attenuation of pregnancy-induced analgesia by hypogastric neurectomy in rats. Brain Res 277: 186-188, 1983.

9. Goland, R. S., S. L. Wardlaw, R. I. Stark and A. G. Frantz. Human plasma $\beta$-endorphin during pregnancy, labor, and delivery. J Clin Endocrinol Metab 52: 74-78, 1981.

10. Kayan, S., L. A. Woods and C. L. Mitchell. Experience as a factor in the development of tolerance to the analgesic effect of morphine. Eur J Pharmacol 6: 333-339, 1969.

11. Kimball, C. D. Do endorphin residues of beta lipotropin in hormone reinforce reproductive functions? Am J Obstet Gynecol 134: 127-130, 1979.
12. Kimball, C. D., C. M. Chang and M. B. Chapman. Endogenous opioid peptides in intrapartum blood. Am J Obstet Gynecol 149: 79-82, 1984

13. Kofinas, G. D., A. D. Kofinas and F. M. Tavakoli. Maternal and fetal $\beta$-endorphin release in response to the stress of labor and delivery. Am J Obstet Gynecol 152: 56-59, 1985.

14. Kristal, M. B. Placentophagia: a biobehavioral enigma (or De gustibus non disputandum est). Neurosci Biobehav Rev 4: 141150, 1980.

15. Kristal, M. B., A. C. Thompson and H. L. Grishkat. Placenta ingestion enhances opiate analgesia in rats. Physiol Behav 35: $481-486,1985$.

16. Kristal, M. B., A. C. Thompson, S. B. Heller and B. R. Komisaruk. Placenta ingestion enhances analgesia produced by vaginal/cervical stimulation in rats. Physiol Behav 36: 1017$1020,1986$.

17. Kristal, M. B., J. F. Whitney and L. C. Peters. Placenta on pups' skin accelerates onset of maternal behavior in nonpregnant rats. Anim Behav 29: 81-85, 1981.

18. Lester, L. and M. S. Fanselow. Exposure to a cat produces opioid analgesia in rats. Behav Neurosci 99: 756-759, 1985.

19. Panerai, A. E., A. Martini, A. M. DiGiulio, F. Fraioli, C. Vegni, G. Pardi, A. Marini and P. Montegazza. Plasma $\beta$-endorphin, $\beta$-lipotropin, and met-enkephalin concentrations during pregnancy in normal and drug-addicted women. I Clin Endocrinol Metab 57: 537-543, 1983.

20. Petraglia, F., M. Baraldi, G. Giarre, F. Facchinetti, M. Santi, A. Volpe and A. R. Genazzani. Opioid peptides of the pituitary and hypothalamus: changes in pregnant and lactating rats. $J$ Endocrinol 105: 239-245, 1985. 
21. Pilkington, J. W., C. B. Nemeroff, G. A. Mason and A. J. Prange. Increase in plasma $\beta$-endorphin-like immunoreactivity at parturition in normal women. Am J Obstet Gynecol 145: $111-113,1983$.

22. Thomas, T. A., J. E. Fletcher and R. G. Hill. Influence of medication, pain, and progress in labour on plasma $\beta$-endorphin-like immunoreactivity. Br J Anaesth 54: 401-408, 1982.
23. Wardlaw, S. L. and A. G. Frantz. Brain $\beta$-endorphin during pregnancy parturition and the postpartum period. Endocrinology 113: 1664-1668, 1983. 